\title{
Compact Heat Exchangers - Design and Optimization with CFD
}

DOI:

10.1016/j.ijheatmasstransfer.2019.118766

\section{Document Version}

Accepted author manuscript

Link to publication record in Manchester Research Explorer

\section{Citation for published version (APA):}

Abeykoon, C. (2019). Compact Heat Exchangers - Design and Optimization with CFD. International Journal of Heat and Mass Transfer. https://doi.org/10.1016/j.ijheatmasstransfer.2019.118766

\section{Published in:}

International Journal of Heat and Mass Transfer

\section{Citing this paper}

Please note that where the full-text provided on Manchester Research Explorer is the Author Accepted Manuscript or Proof version this may differ from the final Published version. If citing, it is advised that you check and use the publisher's definitive version.

\section{General rights}

Copyright and moral rights for the publications made accessible in the Research Explorer are retained by the authors and/or other copyright owners and it is a condition of accessing publications that users recognise and abide by the legal requirements associated with these rights.

\section{Takedown policy}

If you believe that this document breaches copyright please refer to the University of Manchester's Takedown Procedures [http://man.ac.uk/04Y6Bo] or contact uml.scholarlycommunications@manchester.ac.uk providing relevant details, so we can investigate your claim.

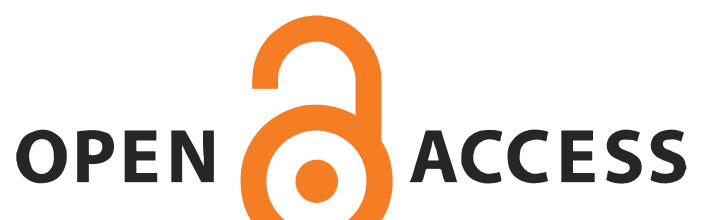




\title{
Compact Heat Exchangers - Design and Optimization with CFD
}

\author{
Chamil Abeykoon \\ Aerospace Research Institute and Northwest Composites Centre, Department of Materials, Faculty of Science and \\ Engineering, The University of Manchester, Oxford Road, M13 9PL, Manchester, UK
}

\begin{abstract}
Heat transfer is one of the key aspects of machineries, devices and industrial processes for maintaining their functionality and also for achieving better product quality. Hence, heat exchangers of different types and sizes are used in these applications with the purpose of removing the extra process/device heat to maintain the desirable working temperatures. However, the size of a heat exchanger is a major consideration for any type of process/device as it decides the space requirements (i.e., the size) of the machine/device or the processing plant. At first, this study aims to investigate the design procedure of a heat exchanger theoretically and then its performance will be analyzed and optimized using computational fluid dynamics. For the design purposes, a counter flow heat exchanger was considered and its length was theoretically calculated with the LMTD method while the pressure drop and energy consumption were also calculated with the Kern method.
\end{abstract} Afterwards, a computational model of the same heat exchanger was implemented with ANSYS and then this model was extended to six different models by altering its key design parameters for the optimization purposes. Eventually, these models were used to analyze the heat transfer behavior, mass flow rates, pressures drops, flow velocities and vortices of shell and tube flows inside the heat exchanger. Theoretical and CFD results showed only a $1.05 \%$ difference in terms of the cooling performance of the hot fluid. The axial pressure drops showed positive correlations with both the overall heat transfer coefficient and pumping power demand. Overall, the results of this study confirms that CFD modeling can be promising for design and optimization of heat exchangers and it allows testing of numerous design options without fabricating physical prototypes.

Keywords: Compact Heat Exchanger, Heat Transfer Enhancement, Fluid Flow Behavior, CFD, LMTD Method, Kern method, Design and Optimization

\section{INTRODUCTION}

Heat transfer can be occurred via three main modes: conduction, convection (free or forced), and radiation. Also, heat transfer can be promoted by artificial approaches while it also occurs naturally from or to a thermodynamic system due to buoyancy forces. Moreover, heat transfer occurs between all live and inanimate things. All the living things are subjected to heat transfer between their body and the surroundings via one or more of the above mentioned modes. One of the best examples is that 
human beings used cooling fans in summer while heaters in winter to maintain their body temperature for its proper functionality. Meantime, animals also use various strategies to maintain their body temperature, or naturally they have supportive organs, for example Sahran silver ants' silver coat helps them to withstand scorching desert heat. Moreover, heat exchanging mechanisms can be found in many of the commonly used small devices/vehicles (such as laptops, tablets, refrigerators, scooters) to very large industrial machineries/vehicles. Hence, heat transfer is one of the immensely important phenomena in our lives and also in most of the modern machineries, devices and processes. It is clear that various types of heat exchanges are widely used in innumerable applications to add or remove heat $[1,2]$. They can be classified based on their flow arrangement (e.g., parallel flow, counter flow, cross flow), construction (shell-and-tube, plate, plate-fin, shell and plate, adiabatic wheel), surface compactness or the number of fluids in use [3-5], and two different types based on the construction are shown in Fig. 1. Heat exchangers allow exchanging heat between two or more media (metals, water, oil, air, etc) for heating and cooling purposes. Currently, many types/sizes of heat exchangers are used in the applications such as refrigeration, air conditioning, automobiles, process industry, solar water heater systems, thermal power plants, and so forth. For all of these applications, the required size of a heat exchanger should be determined based on the amount of heat load to be added or removed from a system at a given time.
Obviously, the size of a heat exchanger is crucial for any application as it is a key factor of deciding the physical size of a component or the space requirements of an industrial process. Also, the size might have some influence on the factors such as the manufacturing cost, portability, appearance, maintenance, etc. Hence, numerous research works are underway to enhance the heat transfer in heat exchangers to replace bulky and less efficient conventional heat exchangers with advanced compact designs, with the aid of modern computer based design and optimization tools, which can be beneficial in various ways [6-10].

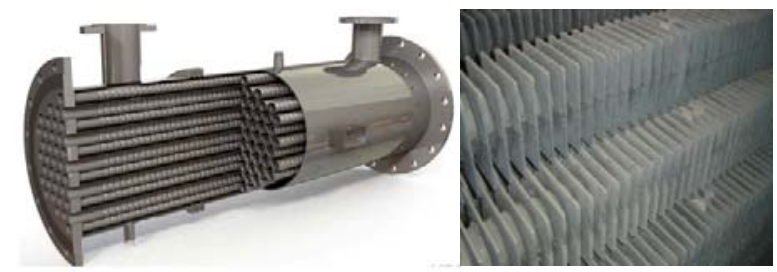

Fig. 1: Different types of heat exchangers based on their construction: (a) - A single pass tubular (left), A plate (right)

Heat transfer performance of heat exchangers can be enhanced by active, passive or compound techniques [11]. Active methods enhance the heat transfer rate via techniques that require external power sources, such as, mechanical aids, injection and suction of the fluid, surface-fluid vibration, jet impingement, use of electrostatic fields, etc. However, these methods may have practical limitations due to their requirement of external power sources for the operation. Passive methods perform the work passively (i.e., without any involvement of external power sources) by improving the heat exchange with some possible techniques such as addition of surface coatings, roughing of surfaces, extended surfaces, placing of 
swirl flow generators (such as different types of vortex generators) across the flow, use of additives with liquids/gases, and so forth. Many of the previous research [12-20] have focused on passive techniques possibly due to the fact that they do not demand an extra energy input. These methods seem to be attractive in practical applications particularly due to their simplicity and low cost. Meantime, compound methods or systems use two or more active or passive techniques to improve the rate of heat transfer. In current industry, it is rudimentary for companies to have cost-efficient heat exchangers with a view on the operational costs, but also the fabrication and materials costs have to be as low as possible as well. Hence, the current industrial focus is to optimise the heat exchanger designs with a view on keeping the pressure drop as low as possible, while retaining the heat transfer coefficient as high as possible. However, all the optimisation tasks always depend on the objective function/s and it is quite difficult to enhance the heat transfer performance of a heat exchanger while minimizing the pressure drop as they usually have negative correlations. Previous studies [21-39] on optimising heat exchanger designs showed that correlations between the pressure drop and heat transfer coefficient are a key in optimising heat exchanger design. Decreasing the pressure drop affects the operating costs positively due to the decrease in required pumping power. By increasing the heat transfer coefficient, the investment costs of the heat exchanger can be decreased with the possible reduction of the required length and material and hence the less complexity in maintenance. But usually, the options to increase the heat transfer coefficient (e.g., decreasing the baffle cut ratio, modifications to the tube bank arrangement, lower baffle spacing) influence the pressure drop negatively and hence such optimization studies presents a complicated task.

\subsection{Shell-and-tube heat exchanger}

This study is focused on modelling of a single pass shell and tube heat exchanger since it is the most commonly used type in industrial applications [40]. Mukherjee [41] claims that nowadays the design of shell-and-tube heat exchangers is mainly carried-out with the help of computational software packages. However, to use such software packages, it is necessary to understand the fundamental principles of a heat exchanger design and its main components (e.g., shell, shell cover, tubes, channel, channel cover, tube sheet, baffles and nozzles, etc). The basic arrangement of a fixed-tube sheet shelland-tube heat exchanger is shown in Figs. 1 and 4 [42] and this type has straight tubes where the stationary tube sheets at both ends are welded to the shell to secure the tubes. Baffles are installed to cause turbulence and cross flow velocity components to increase the convection coefficient of the shell side fluid. It is possible to further enhance the design with removable channel covers, for example. A fixed-tube sheet heat exchanger is an economical option given its simple construction and the cheapest shell-and-tube-heat exchanger type. Moreover, it can be easily dismantled and repaired. The cleaning process can be performed mechanically after 
extracting the bonnet [41]. A U-tube heat exchanger has only one tube sheet, but the lower costs caused by this fact are balanced because of the costs for bending the tubes and the bigger shell diameter. Therefore, its costs of purchase are comparable to a fixed-tube sheet heat exchanger. One of the main advantageous of the U-tube type is the free end with respect to stress differentials, because the tube bundle can be expanded or contracted. However, it is quite difficult to clean inside of the tubes effectively due to the bends. Thus it is not favourable for dirty fluids $[41,43]$.

\subsection{Methods to determine the rate of heat transfer}

The Logarithmic Mean Temperature Difference (LMTD) method $[1-5,43]$ is one of the widely used methods to determine the rate of heat transfer within a heat exchanger. This principle is based on the assumption that a constant wall temperature along the heat exchanger and considers a logarithmic average temperature based on the temperature difference of the cold and hot fluid streams at the each end of the heat exchanger. With given inlet temperatures of the fluids, the outlet temperatures of the fluids can be determined and the energy balance equation can be applied based on the flow arrengement. Subsequently, the heat transfer coefficients in the shell and tubes can be determined, which enables the calculation of the overall heat transfer coefficient. With all of these parameters, the total required length of a heat exchanger can be determined to remove/add a certain heat load. Instead, the Number of Transfer Units (NTU) method can also be applied for calculating the rate of

heat transfer if the inlet temperatures of both fluid streams are known $[1-5,43]$. The main idea of this method is that the heat transfer rate of a heat exchanger of infinite length can be determined as one of the fluids would achieve the maximum potential temperature difference. More details on determining the rate of heat transfer can be found in the literature [1-5].

\subsection{Effect of baffles on the heat exchanger performance}

Some of the most important factors for the performance of a heat exchanger are the baffle design, baffle spacing and the baffle cut ratio and hence the proper implementation of these in CFD platforms are also really important for achieving accurate results. For this study, plate and rod baffles are considered and a few different types of baffles used in practice are shown in Fig. 2.
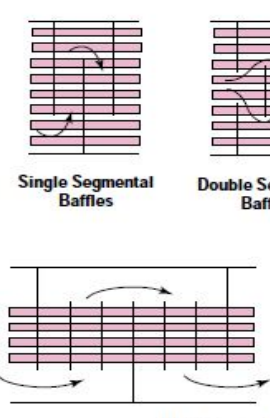

No-Tubes-in-Window Segmental Baffles

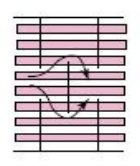

uble Segmental

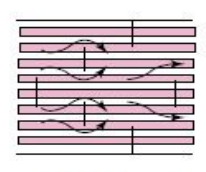

Triple Segmental
Baffles
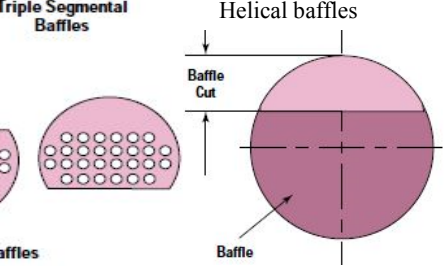

Fig. 2: Different types of baffle arrangements and flow across the baffles [41]

Mainly, baffles are used to direct the flow of the shell side fluid and also to reduce the effects of vibration to the tube bundle. Baffles create a cross flow velocity component which increases the heat transfer coefficient. The baffle spacing is the offset between two adjacent baffles in the same side of the shell (top or bottom) and is a very critical parameter 
in shell-and-tube heat exchanger design which should be chosen appropriately [41]. According to the Tubular Exchanger Manufacturers Association (TEMA) standards, the baffle spacing should not be less than one fifth of the inside diameter of the shell or 2 inch $(50.8 \mathrm{~mm})$, the choice depends on whichever is greater. Lower baffle spacing will result in poor tube bundle penetration and problems in cleaning inside the shell (i.e., outside of the tubes). Also, excessively higher baffle spacing should result in poor heat transfer performance. Furthermore, if the baffle spacing is too wide, there will be no sufficient protection against the tube vibrations generated by the flow of the shell side fluid. Usually, there is a positive correlation between the pressure drop and the heat transfer coefficient, and both are dependent upon the baffle spacing as well. Small baffle spacing enhances the heat transfer coefficient but increases the pressure drop demanding a higher pumping power and vice versa. Another important factor associated to the baffle design is the baffle cut ratio which is defined as a percentage to the shell inner diameter (see Fig. 2). The baffle cut can be between $15-45 \%$, but it is suggested to use a baffle cut ratio in the range of $20-35 \%$ for optimum performance [41]. Designs with a baffle cut ratio less than $20 \%$ increase the heat transfer coefficient while the designs above $35 \%$ decrease the pressure drop. But in both cases the final result may not be optimal. Hence, finding of an optimal balance between the baffle cut ratio and baffle spacing is a key aspect of a well-designed heat exchanger in terms of the constructional and thermal aspects. The possible effects of baffle spacing and baffle cut ratio on the flow behavior are shown in Fig. 3.

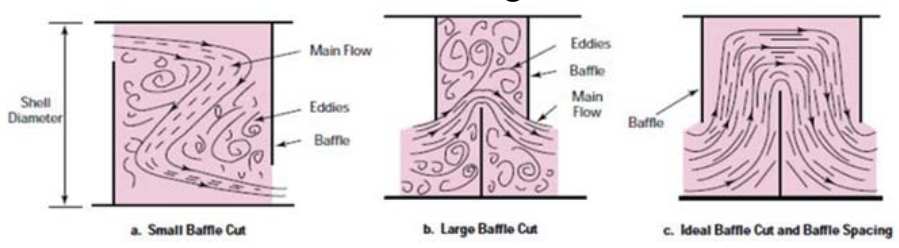

Fig. 3: Flow behavior based on baffle cut ratio and baffle spacing [41]

Liu et al. [30] stated that heat exchangers with segmental baffles are the most industrially common shell-and-tube type. However, due to the possible disadvantages such as high pumping power, fouling problems in the dead zones, and the absence of sufficient prevention for vibrations, it is necessary to come-up with advanced/improved designs to avoid or narrow these limitations. Therefore, they developed a heat exchanger with eccentric twisted tubes (with no baffles), which are in contact at a lot of points along the length of the tubes in the bundle, and this design lowered the possibilities of vibrations of tubes. The results were better compared to a rod baffle shell-and-tube heat exchanger. Another advantage of this design is the increase in heat transfer area which leads to a highly compact design. Hence, heat exchangers without baffles may be a good alternative for the future industry. However, due to the limited space among the tubes, the pressure drop might increase substantially and also there will be issues of cleaning and maintenance and hence this design might not be industrially attractive.

\subsection{Previous optimization studies with PSO and GA}

Nowadays techniques such as genetic algorithm (GA), differential evolution (DE), particle swarm 
optimization (PSO), and simulated annealing (SA) have become more and more popular and applied in product design and optimization. Liu et al. [21] describe how to design and optimise a heat exchanger on the basis of constructal theory [44]. In this method, a heat exchanger is segmented into several parts and then the each part is optimised by adjusting the parameters via a genetic algorithm. Such optimization work should help to improve the hydraulic efficiency and cost factors and also to decrease the irreversible power losses as effectively as achievable. The results showed that the costs compared to the original design were reduced. Another case study performed by Amidpour et al. [22], a method was proposed with the constructal theory to decrease the total costs by optimising the overall heat transfer coefficient with regard to the tube diameters. With a higher heat transfer coefficient, the rate of heat transfer will be enhanced and hence the size of the heat exchanger can be reduced which enables capital savings. Furthermore, some other works have performed optimisation case studies with genetic algorithms but without using the constructal theory. Hajabdollahi et al. [23] designed a heat exchanger by following the NTU method and optimised via a genetic algorithm with the objectives of maximizing the effectiveness and reducing the total costs. The results showed that the design parameters like tube pitch ratio, tube length, number of tubes and baffle spacing caused some problems in achieving both objectives simultaneously. Generally, with these types of optimisation approaches, an increase in the total cost is possible with the increase of the effectiveness and hence multi-objective optimisation approaches should be useful for optimal heat exchanger designs.

Patel et al. [24] used a PSO to improve the performance of a shell-and-tube heat exchanger. The heat transfer coefficient was increased by increasing the fluid velocities. The results were compared with a genetic algorithm for the same application and better performance (with a cost reduction) was achieved than with GA.

Work by Benetto et al. [25] claimed that although the heat transfer coefficients are higher with turbulent flow conditions, laminar flows need to be used when it is required to decrease the pressure drop. They tested a new technique to increase the convective heat transfer coefficient of a short pinfins system without inducing further pressure drops and this gave a $10 \%$ increase to the Nusselt number.

Fukai et al. [26] claimed that the best possible ways for improving the overall heat transfer coefficient are either by increasing the heat transfer surface area or by the refinement of the heat transfer coefficient. They enhanced the heat transfer coefficient significantly by using a sheet-fin mechanism via increasing the heat transfer surface area of a heat exchanger. Particularly this method is suitable for tube bank arrangements with long pitches.

Fettaka et al [45] proposed a multi-objective optimization to minimize the heat transfer surface area and pumping power of a shell-and tube heat exchanger which can provide with multiple Paretooptimal solutions capturing the compromise between objectives. A genetic algorithm was used with nine 
decision variables and found that the discretization of the tube diameter, length and thickness can provide only a very minor effect on the optimal cost design.

\subsection{Previous optimization studies with CFD approaches}

With the development of computational technologies, computational fluid dynamics (CFD) approaches are also becoming popular in design optimization. As was stated by Ahmad et al. [46], both LMTD and NTU methods demonstrate some deficiencies and hence the designs made by these theoretical methods needs to have a prototype to test their performance. Development of prototypes should be costly and time consuming and also another drawback is that a new prototype is required for each new design which would be really impractical. Thus, CFD approaches should be really attractive for testing the performance of any number of new designs without fabricating prototypes. CFD approaches solve the complete system by putting it into small cells or grids. Then CFD packages use governing equations to solve the cells numerically in terms of pressure distribution, temperature parameters, flow behaviour, flow rates and so forth. Furthermore, CFD approaches can be used with any heat exchanger type, where the $K-\varepsilon$ model is the most widely used model in heat exchanger design from a wide array of turbulence models available in CFD platforms.

Pal et al [47] used CFD to study the effects of baffles on the performance of four different types of short heat exchangers. The results showed that the cross flow near the nozzle region has a significant contribution towards the heat transfer and hence the conventional heat transfer correlations might not adhere to these type of short heat exchangers. A sensitivity study showed that of the turbulence models tested, the standard $\mathrm{k}-\varepsilon$ model was capable of providing the most accurate results on velocity profile and heat transfer. The proposed CFD model predicted the pressure drop with a $\pm 10 \%$ difference to the values estimated with the Bell-Delaware method for heat exchanger designs with baffles.

Bichkar et al [48] used CFD approaches to investigate the effect of baffles on the performance of a shell-and-tube heat exchanger and found that helical baffles gave better performance compared to single-segmental and double-segmental baffles. Of the three types tested, single-segmental baffles gave the worst heat transfer performance (i.e., with dead zones) with the highest pressure drop. Also, increasing the number of baffles causes to increase the pressure drop as was expected.

Tay et al [49] compared a CFD and an effectiveness-number of transfer units ( $\varepsilon$-NTU) models with the experimental measurements made in a large phase change materials tank. Experimental measurements were taken at 12 different locations of the tank and they showed good agreement with CFD and $\varepsilon-\mathrm{NTU}$ models. However, the CFD model did not consider the effects of natural convection and buoyancy effects and hence showed some slight mismatches with experimental and $\varepsilon-\mathrm{NTU}$ results.

Shahril et al. [50] employed the commercially available CFD software ANSYS FLUENT to model 
the performance of a shell-and-double concentric tube heat exchanger (SDCTHE). They observed the effect of inner tube diameter on heat transfer performance of a SDCTHE and a typical shell-andtube heat exchanger (STHE). The results showed that a SDCTHE can improve the overall heat transfer rate per overall pressure drop of up to $343 \%$ while reducing the total friction power by around $85.5 \%$ compared to a STHE with the same configuration. Moreover, their findings confirmed that the SDCTHEX was able to achieve a higher heat transfer performance while maintaining a lower pressure drop. Also, a conclusion was made that a higher effectiveness may be achieved with lower inner tube diameters and also with higher hot fluid mass flow rates and hence would be economical.

Bock et al. [29] performed 3-D numerical simulations for a shell-and-tube heat exchanger with rod-baffles using four different models: a unit model, a periodic model, a porous model and a whole model. These models showed good performance with the enhancement of heat transfer where the unit model had the lowest accuracy of the four models. The porous and whole models demonstrated a high precision in predicting the pressure drop while unit and periodic models were unable to directly predict the hydraulic performance. The whole model showed the highest precision among all models but it demanded high performance computing as it had the largest number of cells among four models.

Ozden et al. [28] tested a shell-and-tube heat exchanger using two CFD turbulence flow models: $K-\varepsilon$ and Spalart-Allmaras. Particularly the effects of baffle cut ratio, number of baffles, baffle spacing and shell diameter towards the heat transfer coefficient and the pressure drop were studied. They claimed that the CFD results are in agreement with the Bell-Delaware method with regard to the heat transfer coefficient. At present the Bell-Delaware method [51] is widely used in industry for heat exchanger design and also their results demonstrated that CFD is a useful and trustworthy tool for heat exchanger design. Use of CFD software packages together with validation experiments should be an effective approach to achieve fast results in shelland-tube heat exchanger design.

\subsection{Previous studies based on numerical and other approaches}

Yang et al [52] came-up with a new single shellpass shell-and-tube heat exchanger design with twolayer continuous helical baffles. Numerical simulation showed that this new design can enhance the heat transfer performance with a considerably lower pressure drop (and hence lower pumping power) compared to commonly used shell-and-tube heat exchangers with continuous helical baffles. Usually, achieving of an increase in heat transfer and a decrease in pressure drop in simultaneous manner is quite difficult as they have a negative correlation. Hence, this design would be promising for compact heat exchanger design if it is industrially viable.

Wang et al [53] performed a thermodynamics analysis (i.e., to explore fluid flow and heat transfer characteristics) in relating to the tube bank of a cross-flow heat exchanger and the shell side of a shell-and-tube heat exchanger. They found that the 
fluid flow and heat transfer characteristics are independent form the degree of inclination of tubes in a cross-flow heat exchanger while these were greatly dependent upon the vertical velocity component of the fluid in the shell side of a shelland-tube exchanger. Also, they observed the effect of different baffle geometries on fluid flow velocity which was quit significant as can be expected. A few other works [54-58] also have provided reviews on design and operation of compact heat exchangers and can be found in the literature.

In terms of the heat exchanger design aspects, this study aims to study the effects of baffle cut ratio and the number of tubes within the shell towards the performance of a shell-and-tube heat exchanger. Furthermore, CFD models will be used in design optimization by analysing the heat transfer behaviour, mass flow rates, pressures drops, flow velocities and vortices of shell and tube fluid flows inside the heat exchanger. Particularly, this work contributes on heat exchanger design and optimization while extending the understanding on heat transfer and fluid flow behaviour of shell-andtube-type heat exchangers.

\section{METHODOLOGY}

Here, a specific heat transfer question was selected and at first it was solved theoretically with the Logarithmic Mean Temperature Difference (LMTD) method. Then, the same model was implemented on a CFD platform (ANSYS FLUENT) and then the CFD model was validated. Eventually, the validated CFD model was used for an optimization study by changing the key design parameters but considering the same heat transfer load. Altogether six different CFD models were developed and tested, and more details are given in the following sections.

\section{THE THERITICAL DESIGN OF THE HEAT EXCANGER}

The design considered in this work is a single pass fixed-tube sheet shell-and-tube heat exchanger as it is the most common type used in practice. It has a tube bundle with straight tubes and the tube bank arrangement is in staggered design to increase the heat transfer coefficient as shown in Fig. 4.

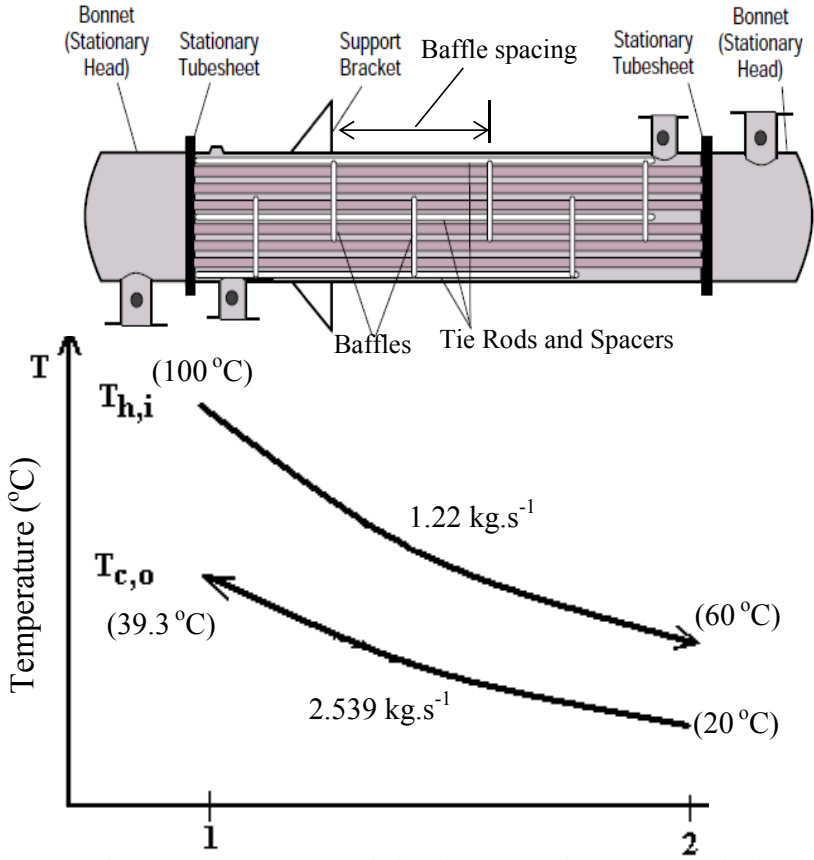

Fig. 4: The arrangement of the heat exchanger with its T$\mathrm{x}$ diagram

Baffles are installed to cause turbulence and cross flow velocity components to increase the convection coefficient of the shell side fluid, the working fluids enter at the opposite ends (i.e., a counter flow) of the heat exchanger. Thus, combined effects of cross and counter flow arrangements occur in this heat 
exchanger design. The installed baffles also prevent deflection to the tube bundle and effects of vibration caused by the shell side fluid stream. The tube sheets are welded to the shell body and also secure the tubes. The case study considered was to cool down a hot fluid at $100{ }^{\circ} \mathrm{C}$ to $60{ }^{\circ} \mathrm{C}$ by transferring the heat load to a counter flowing cold fluid. Water was taken as both the hot and cold fluids and the hot fluid was set inside the tubes while the cold fluid was flowing across the outer surfaces of the tubes inside the shell. To exchange the given heat load, the required length of the heat exchanger was theoretically determined by considering all related factors together with the resulting axial pressure drop and total pumping power demand. The arrangement of the heat exchanger and the corresponding Temperature-Axial Distance (T-x diagram) with some key parameters are shown in Fig. 4.

Based on the selected specifications of the case study, the required length of the heat exchanger was calculated as presented below. Properties of the hot fluid (water) and cold fluid (water) streams at their average temperatures $\left(T_{h, a v g}\right.$ and $\left.T_{c, a v g}\right)$ are listed in Table 1 followed by the assumptions associated to the theoretical calculations.

Table 1: Properties of hot and cold fluids at their average temperatures

\begin{tabular}{|l|l|}
\hline \multicolumn{1}{|c|}{ Hot fluid } & \multicolumn{1}{c|}{ Cold fluid } \\
\hline$T_{h, a v g}=80^{\circ} \mathrm{C}=353.15 \mathrm{~K}$ & $T_{c, a v g}=29.65^{\circ} \mathrm{C}=302.8 \mathrm{~K}$ \\
\hline$c_{p h}=4197 \mathrm{~J} \cdot \mathrm{kg}^{-1} \cdot \mathrm{K}^{-1}$ & $c_{p c}=4179 \mathrm{~J} \cdot \mathrm{kg}^{-1} \cdot \mathrm{K}^{-1}$ \\
\hline$P r_{h}=2.22$ & $P r_{c}=5.43$ \\
\hline$\mu_{h}=0.355 \times 10^{-3} \mathrm{~Pa} . \mathrm{s}$ & $\mu_{c}=0.798 \times 10^{-3} \mathrm{~Pa} . \mathrm{s}$ \\
\hline$k_{h}=0.670 \mathrm{~W} \cdot \mathrm{m}^{-1} \cdot \mathrm{K}^{-1}$ & $k_{c}=0.615 \mathrm{~W} \cdot \mathrm{m}^{-1} \cdot \mathrm{K}^{-1}$ \\
\hline
\end{tabular}

where, $c_{p}$ is the specific heat capacity at constant pressure, $P r$ is the Prandtl number, $\mu$ is the viscosity and $k$ is the thermal conductivity. Subscripts $h$ and $c$ refer to the hot and cold fluids, respectively.

Assumptions:

- Heat losses to the surroundings are negligible.

- Constant properties of the working fluids within the heat exchanger.

- Kinetic and potential energy changes are negligible.

- No fouling.

- Thin walled tubes and hence tubes' wall thermal resistance is negligible.

- Fully developed flow conditions of both fluid streams.

\subsection{Calculating the required length of the heat exchanger}

First, the mass flow rate of the hot fluid stream $\left(m_{h}\right)$ should be determined with the known inlet and outlet temperatures from Eq. (1): $\dot{m}_{h}=\rho_{h} \times v_{\text {tube }} \times A_{\text {tube }}=971.8 \times 4 \times 0.000314=$ $1.22 \mathrm{~kg} . \mathrm{s}^{-1}$

where $\rho_{h}$ is the density of the hot fluid, $v_{\text {tube }}$ is the velocity of the fluid inside the tubes and $A_{\text {tube }}$ is the cross sectional area of the tubes. Then the heat load (q) removed from the hot fluid or absorbed by the cold fluid can be obtained from Eq. (2):

$q=\left(\dot{m} c_{p}\right)_{h}\left(T_{h, i}-T_{h, o}\right)=\left(\dot{m} c_{p}\right)_{c}\left(T_{c, i}-T_{c, o}\right)$

$q=1.22 \times 4197 \times(100-60)=204.814 \mathrm{~kW}$

where $T$ is the temperature while subscripts $i$ and $o$ represent the inlet and outlet conditions. Thereafter, the design of the shell and the tube bank arrangement was considered. For the tube bank arrangement, the 
staggered design was chosen for this study (as shown in Fig. 5) because the first rows in the tube bank act as a turbulent grid for the following rows, which causes to increase the heat transfer coefficient [44]. Here, $S_{L}, S_{D}$ and $S_{T}$ stand for longitudinal, diagonal and transverse pitch values, respectively.

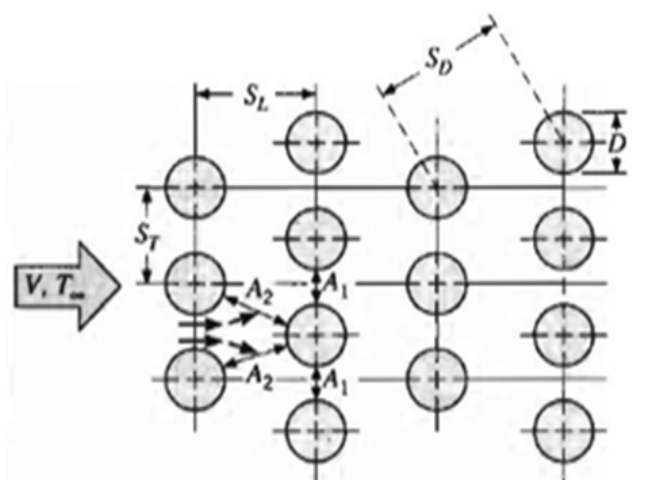

Fig. 5: Staggered tube bank arrangement [44]

The tube bank has four rows in both longitudinal and transverse directions. Wilson and Bassiouny [27] found that pressure drop and friction factor might increase with the increase of the longitudinal pitch $S_{L}$. As they proposed, the pitch ratio $\left(\mathrm{S}_{\mathrm{L}} / \mathrm{D}_{\text {tube }}\right)$ for a staggered design should be less than or equal to 1.5 $\left(\mathrm{S}_{\mathrm{L}} / \mathrm{D}_{\text {tube }} \leq 1.5\right)$ to achieve a compact heat exchanger. Therefore, both longitudinal and transverse pitch ratios were chosen as $S_{L} / D_{\text {tube }}=1.5$ and $\mathrm{S}_{\mathrm{T}} / \mathrm{D}_{\text {tube }}=1.5$ (see Fig. 5). Here, the diagonal pitch can be determined from Eq. (3).

$S_{D}=\sqrt{S_{L}{ }^{2}+\left(\frac{S_{T}}{2}\right)}=\sqrt{30^{2}+\left(\frac{30}{2}\right)^{2}}=33.54 \mathrm{~mm}$

With a known pitch ratio and the number of rows of tubes, the shell diameter $\left(D_{\text {shell }}\right)$ was obtained from Eq. (4):

$D_{\text {shell }}=S_{T}\left(N_{R}+2\right)=30 \times(4+2)=180 \mathrm{~mm}$

where $N_{R}$ is the number of tubes per row. With the shell diameter, the cross sectional area of the shell was determined. Subsequently, the mass flow rate of the cold fluid inside the shell $\left(\dot{m}_{c}\right)$, which depends on the cross sectional area of the shell inlet was obtained from Eq. (5):

$\dot{m}_{c}=\rho_{c} \times v_{\text {inlet }, \text { shell }} \times A_{\text {inlet, shell }}=995.7 \times$

$1.25812 \times 0.002026=2.539 \mathrm{~kg} \cdot \mathrm{s}^{-1}$

where $\rho_{c}$ is the density of the cold fluid inside the shell, and $A_{\text {inlet,cold }}$ is the cross sectional area of the shell inlet. After determining the mass flow rate of the cold fluid in the shell, the outlet temperature of the cold fluid stream can be obtained from Eq. (6):

$T_{c, o}=\frac{q}{\dot{m}_{c} \times c_{p c}}+T_{c, i}=\frac{204814}{2.539 \times 4179}+20=39.3^{\circ} \mathrm{C}$

The Logarithmic Mean Temperature Difference $\left(\Delta T_{l m}\right)$ which is a logarithmic intersection of the cold and hot fluid streams at each end of the heat exchanger is given for a counter flow arrangement by the relation given in Eq. (7).

$$
\begin{aligned}
\Delta T_{l m}= & \frac{\left(T_{h, i}-T_{c, o}\right)-\left(T_{h, o}-T_{c, i}\right)}{\ln \left(\frac{\left(T_{h, i}-T_{c, o}\right)}{\left(T_{h, o}-T_{c, i}\right)}\right)} \\
= & \frac{(100-39.3)-(60-20)}{\ln \left(\frac{(100-39.3)}{(60-20)}\right)}=49.59^{\circ} \mathrm{C}
\end{aligned}
$$

The heat exchanger considered in this study is not having a pure counter flow arrangement due to the baffles in the shell side and hence a correction factor (F) for $\Delta T_{l m}$ should be obtained from Fig. 6, after determining related $R$ and $P$ values related to inlet/outlet temperatures from Eqs. (8) and (9).

$$
\begin{aligned}
& R=\frac{T_{s, i}-T_{s, o}}{T_{t, o}-T_{t, i}}=\frac{20-39.3}{60-100}=0.48 \\
& P=\frac{T_{t, o}-T_{t, i}}{T_{s, i}-T_{t, i}}=\frac{60-100}{20-39.3}=0.5
\end{aligned}
$$




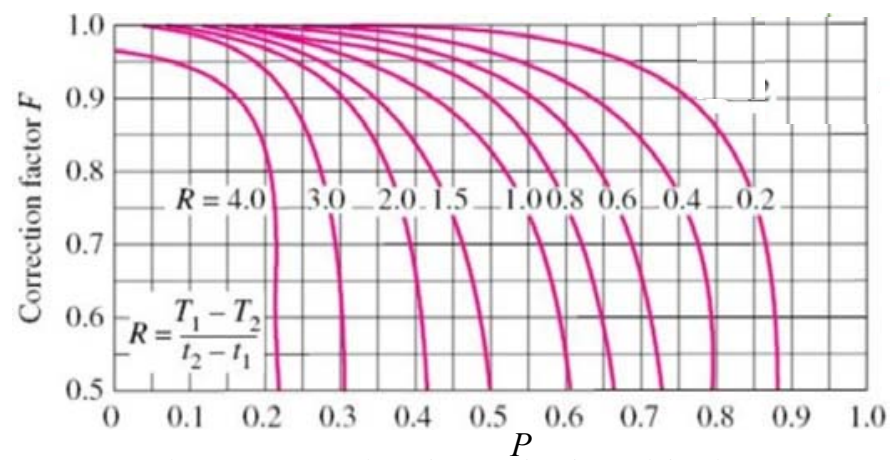

Fig. 6: Correction factor for logarithmic mean temperature difference (single-pass cross-flow with one fluid mixed and the other unmixed) [41]

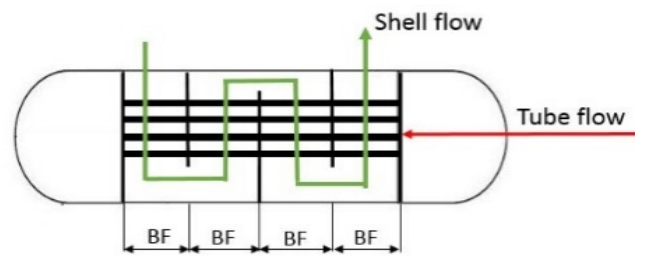

Fig. 7: Schematic shown the baffle spacing (BF) Then the baffle spacing (BF) which is illustrated in Fig. 7, can be determined by Eq. (10):

$B F=\frac{2}{3} D_{\text {shell }}=\frac{2}{3} \times 180=120 \mathrm{~mm}$

Then, the flow area is defined by Eq. (11):

$A_{\text {flow }}=B F \times D_{\text {shell }}=0.12 \times 0.18=0.0216 \mathrm{~m}^{2}$

For a staggered arrangement, the maximum possible velocity $\left(V_{\max }\right)$ could occur through the area $A_{1}$ or $A_{2}$ shown in Fig. 5, whichever is smaller. The first step is to obtain $V_{\max }$ for calculating $V_{\infty}$ from Eq. (12).

$V_{\infty}=\frac{\dot{m}_{c}}{\rho_{c} \times A_{\text {flow }}}=\frac{2.539}{995.7 \times 0.0216}=0.12 \mathrm{~m} . \mathrm{s}^{-1}$

For a staggered arrangement, the following conditions also have to be checked:

$S_{D}<\frac{S_{T}+D_{\text {tube }}}{2}, \quad S_{D}<\frac{30+20}{2}=25 \mathrm{~mm}$

As was calculated by Eq. (3), $S_{D}=33.54 \mathrm{~mm}$ and hence this condition is not satisfied. Also the velocity $V_{2}$ is greater than $V_{1}$, which means that $V_{2}=V_{\max }$ and has to be calculated from Eq. (14).

$V_{2}=\frac{S_{T}}{2 \times\left(S_{D}-D_{\text {tube }}\right)} \times V_{\infty}$
If the relation from Eq. (13) is not true, which is the case for this study, then $V_{1}=V_{\max }$ and has to be determined from Eq. (15):

$V_{1}=\frac{S_{T}}{S_{T}-D_{\text {tube }}} \times V_{\infty}=\frac{30}{30-20} \times 0.12=0.36 \mathrm{~m} \cdot \mathrm{s}^{-1}$

This heat exchanger has 16 tubes inside the shell $(N)$ and also a triangular pitch layout of the tubes. Hence, the hydraulic diameter for the shell $\left(D_{H-S}\right)$ can be obtained from Eq. (16).

$D_{H-S}=\frac{4 \times \text { Cross Sectional Area }}{P_{\text {wetted }}}=\frac{3.46 S_{T}^{2}}{\pi D_{\text {tube }}}-D_{\text {tube }}$

$D_{H-S}=\frac{3.46 \times 0.03^{2}}{\pi \times 0.02}-0.02=0.0296$

where $P_{\text {wetted }}$ is the wetted perimeter. After determining $V_{\max }$ and the hydraulic diameter $\left(D_{H-S}\right)$, the Reynolds number for the shell side fluid $\left(R e_{s}\right)$ can be calculated from Eq. (17).

$R e_{s}=\frac{\rho_{s} \times V \times D_{H-S}}{\mu_{s}}=\frac{995.7 \times 0.36 \times 0.0296}{0.798 \times 10^{-3}}=13296$

Where $V$ is the velocity based on the actual cross sectional area of the duct or pipe (here $V_{\max }$ was used). Reynolds number explains the nature of the flow of a flowing fluid. If the Reynolds number $R e<2000$ the flow is laminar. This means a constant fluid motion with smooth streamlines. If the Reynolds number is in a range of $2000<R e<$ 4000 , the flow is transitional. It can be interpreted as a combination of turbulent and laminar flow behaviours. If the Reynolds number $R e>4000$, the flow is turbulent [3]. After determining the Reynolds number, the Nusselt number $(N u)$ can be calculated from the correlation given in Eq. (18). The related conditions of $N u$ and the Prandtl number for the shell side fluid $\left(P r_{s}\right)$ are given below:

$$
\begin{gathered}
N_{L} \geq 10 \\
2000 \leq R e_{s} \leq 40000 \\
P r_{S} \geq 0.7
\end{gathered}
$$


$\overline{N u}_{s}=1.13 \times C_{1} \times \operatorname{Re}_{s}{ }^{m} \times \operatorname{Pr}_{s}{ }^{\frac{1}{3}}$

$$
=1.13 \times 0.578 \times 13296^{0.562} \times 5.43^{\frac{1}{3}}=238.49
$$

where $N_{L}$ is the number of rows in the tube bank, $C_{1}$ and $m$ are correction factors which depend on the ratio of $S_{L} / D_{\text {tube }}$ and $S_{T} / D_{\text {tube }}$ which were explained above. The pitch ratio used has passable values for $C_{1}$ and $m$. This fact guarantees a high Nusselt number and hence a high heat transfer coefficient. The relevant Prandtl number can be obtained from the property tables [3]. As the number of rows in the tube bank $N_{L}<10$, the Nusselt number has to be multiplied by a correction factor $C_{2}$.

$\overline{N u}_{s}=C_{2} \times 419.08=0.89 \times 238.49=212.26$

After determining the Nusselt number, the heat transfer coefficient of the shell side fluid $\left(h_{\text {shell }}\right)$ can be obtained from Eq. (19).

$$
\begin{array}{r}
h_{\text {shell }}=\frac{\overline{N u}_{s} \times k_{c}}{D_{H-S}}=\frac{212.30 \times 0.615}{0.0296} \\
=4410.13 \mathrm{~W} \cdot \mathrm{m}^{-2} \cdot \mathrm{K}^{-1}
\end{array}
$$

where $k_{c}$ is the thermal conductivity of the cold fluid. The heat transfer coefficient depends on the boundary layer conditions and the properties of the fluid in motion [3]. To obtain the heat transfer coefficient associated to the shell side fluid $\left(h_{\text {tube }}\right)$, the mean velocity of tube side fluid $\left(V_{m-t u b e}\right)$ needs to be determined from Eq. (20).

$$
\begin{array}{r}
V_{m-\text { tube }}=\frac{\dot{m}_{h}}{\rho_{h} \times A_{\text {tube }} \times N}=\frac{1.22}{=0.25 \mathrm{~m} . \mathrm{s}^{-1}}=\frac{(20)}{971.8 \times 0.000314 \times 16} \\
\end{array}
$$

Then, the hydraulic diameter for the tube $\left(D_{H-t}\right)$ can be obtained from Eq. (21).

$$
\begin{gathered}
D_{H-t}=\frac{4 \times \text { Cross Sectional Area }}{P_{\text {wetted }}}=\frac{4 \times \frac{\pi \times D_{\text {tube }}{ }^{2}}{4}}{\pi \times D_{\text {tube }}} \\
=0.02 \mathrm{~m}(21)
\end{gathered}
$$

Then the Reynolds number associated to the tube side fluid $\left(R e_{t}\right)$ can be calculated from Eq. (22).

$$
R e_{t}=\frac{\rho_{h} \times V_{m-t u b e} \times D_{H}}{\mu_{h}}=\frac{971.8 \times 0.25 \times 0.02}{0.355 \times 10^{-3}}
$$

With the Reynolds number of tubes' flow, the Nusselt number of the tube flow can be determined based on the following conditions and hence the heat transfer coefficient of the tube side fluid also can be obtained.

$$
\begin{gathered}
{\left[\begin{array}{c}
0.6 \leq P r_{t} \leq 160 \\
R e_{t} \geq 10000
\end{array}\right]} \\
\overline{N u}_{t}=0.023 \times R e_{t}^{\frac{4}{5}} \times P r_{t}{ }^{0.3}=\frac{h_{\text {tube }} \times D_{\text {tube }}}{k_{h}} \\
h_{\text {tube }}=0.023 \times 13680.81^{\frac{4}{5}} \times 2.22^{0.3} \times \frac{0.670}{0.02} \\
=1993.28 \mathrm{~W} \cdot \mathrm{m}^{-2} \cdot \mathrm{K}^{-1}
\end{gathered}
$$

As the heat transfer coefficients in the shell and tube side fluids are available, the overall heat transfer coefficient of the heat exchanger $(U)$ can be obtained from Eq. (24).

$\frac{1}{U}=\frac{1}{h_{\text {shell }}}+\frac{1}{h_{\text {tube }}} \frac{1}{4410.13}+\frac{1}{1993.28}$

$U=1372.80 \mathrm{~W} \cdot \mathrm{m}^{-2} \cdot \mathrm{K}^{-1}$

Then with all the calculated parameters, the total length of the heat exchanger $(L)$ can be determined, which is defined as the length of the tubes, from Eq. (25).

$q=U \times A_{\text {Total }} \times F \times \Delta T_{l m} \times N$

where $A_{\text {Total }}$ is the total heat surface area of the tubes: $\pi \times D_{\text {tube }} \times L$. By substituting $A_{\text {Total }}$ :

$q=U \times \pi \times D_{\text {tube }} \times L \times F \times \Delta T_{l m} \times N$

Subsequently, $L$ can be determined:

$$
\begin{aligned}
& L=\frac{q}{U_{A} \times \pi \times D_{\text {tube }} \times F \times \Delta T_{l m} \times N} \\
& =\frac{204813.6}{1372.8 \times 16 \times \pi \times 0.02 \times 0.96 \times 49.59}=3.12 \mathrm{~m}
\end{aligned}
$$


Finally, with the calculated length, the required number of baffles can be determined from Eq. (26).

$n+1=\frac{L}{B F}=\frac{3.12}{0.12}=26$
$n=26-1=25$ baffles

\subsection{Pressure drop calculations}

The pressure drop calculations of the heat exchanger were carried out by using the Kern Method [59, 60]. To determine the shell side pressure drop $\left(\Delta P_{\text {shell }}\right)$, initially the friction factor of the shell side flow ( $\left.f_{\text {shell }}\right)$ was determined from Eq. (27).

$f_{\text {shell }}=\exp \left(0.576-0.19 \ln \left(R e_{s}\right)\right)$

$f_{\text {shell }}=\exp (0.576-0.19 \ln (13296))=0.2928$

Then the flow area between two tubes was determined from Eq. (28).

$$
\begin{gathered}
A_{s}=\frac{D_{\text {shell }} \times C_{\text {tube }} \times B F}{S_{L}}=\frac{0.18 \times 0.01 \times 0.12}{0.03} \\
=0.0072 \mathrm{~m}^{2}
\end{gathered}
$$

where $C_{\text {tube }}$ is the clearance between adjacent tubes.

With this area, the mass velocity of the shell side fluid $\left(G_{s}\right)$ was determined from Eq. (29).

$G_{s}=\frac{\dot{m}_{c}}{A_{s}}=\frac{2.539}{0.0072}=352.638 \mathrm{~kg} \cdot \mathrm{m}^{-2} \cdot \mathrm{s}^{-1}$

Subsequently the pressure drop in the shell side fluid was determined for Eq. (30).

$\Delta P_{\text {shell }}=\frac{f \times G_{S}{ }^{2} \times(n+1) \times D_{\text {shell }}}{2 \times \rho_{c} \times D_{H-S} \times \varphi_{S}}$

$=\frac{0.2928 \times 352.638^{2} \times 26 \times 0.18}{2 \times 995.7 \times 0.0296 \times 0.2845}=10161.14 \mathrm{~Pa}$

where $\varphi_{S}$ is the viscosity correction factor for the shell side fluid. For the tubes side pressure drop $\left(\Delta P_{\text {tube }}\right)$ the first step is also to calculate the friction factor of the tube side flow $\left(f_{\text {tube }}\right)$. For the tube side fluid it can be obtained from Eq. (31).

$f_{\text {tube }}=\left(1.58 \times \ln \left(R e_{t}\right)-3.28\right)^{-2}$

$f_{\text {tube }}=(1.58 \times \ln (13860.81)-3.28)^{-2}=0.00722$
Then the tube side pressure drop can be determined from Eq. (32).

$$
\begin{aligned}
\Delta P_{\text {tube }}=(4 \times & \left.f_{\text {tube }} \times \frac{L \times N_{\text {passes }}}{D_{\text {tube }}}+4 \times m\right) \\
& \times \frac{\rho_{h} \times V_{\text {mtube }}}{2} \quad(32) \\
\Delta P_{\text {tube }}=(4 \times & \left.0.00722 \times \frac{3.12 \times 1}{0.02}+4 \times 25\right) \\
& \times \frac{971.8 \times 0.25^{2}}{2}=136.819 \mathrm{~Pa}
\end{aligned}
$$

\subsection{Calculation of total power consumption}

The total pumping power of a heat exchanger was calculated previously by Liu et al. [21] with a constant pump efficiency of 0.7 . Based on the same method, the pumping power demand $\left(W_{\text {Pump }}\right)$ of the heat exchanger was calculated from Eq. (33).

$$
\begin{gathered}
W_{\text {Pump }}=\frac{1}{\eta_{\text {Pump }}}\left(\frac{\dot{m}_{c}}{\rho_{c}} \Delta P_{\text {shell }}+\frac{\dot{m}_{h}}{\rho_{h}} \Delta P_{\text {tube }}\right) \\
W_{\text {Pump }}=\frac{1}{0.7}\left(\frac{10161.98 \times 2.539}{995.7}+\frac{136.82 \times 1.22}{971.8}\right) \\
=37.26 \mathrm{~W}
\end{gathered}
$$

\section{THE COMPUTATIONAL FLUID DYNAMICS (CFD) DESIGN OF THE HEAT EXCANGER}

CFD is an established method of solving fluid dynamics problems by using numerical methods such as: Navier-Stokes-Equations [41], EulerEquations [42] or Partial-Differential Equations [43]. Therefore, a CFD approach is an economical alternative to wind tunnel or water tunnel testing or to the fabrication of other kinds of prototypes for testing purposes [44]. In this study, the theoretically tested heat exchanger design was implemented on the CFD software platform ANSYS Workbench 15.0 (i.e., the CFD HE 30 CFD model). Altogether six different arrangements (six CFD models) of the heat exchanger (HE) were implemented with CFD for 
testing, and their key design information together with a summary of the theoretical calculation details is given below in Tables 2 and 3 .

CFD HE 20: no. of tubes - 16, no. of baffles - 25, baffle cut ratio - $20 \%$ CFD HE 30: no. of tubes - 16, no. of baffles - 25 , baffle cut ratio - $30 \%$ CFD HE 12 tubes: no. of tubes - 12, no. of baffles - 25, baffle cut ratio - 30\% CFD HE 20 tubes: no. of tubes - 20, no. of baffles - 25, baffle cut ratio - 30\% CFD HE 24 baffles: no. of tubes - 16, no. of baffles - 24, baffle cut ratio - 30\% CFD HE 26 baffles: no. of tubes - 16, no. of baffles - 26, baffle cut ratio - $30 \%$

Table 2: Design specifications of theoretical design and each CFD model

\begin{tabular}{|l:c|l|l|l|l|l|l|l|}
\hline Parameter & $\begin{array}{l}\text { Unit } \\
\text { Theoretical }\end{array}$ & $\begin{array}{l}\text { CFD HE } \\
\text { values }\end{array}$ & $\begin{array}{l}\text { CFD HE } \\
20\end{array}$ & $\begin{array}{l}\text { CFD HE } \\
\text { 12 tubes }\end{array}$ & $\begin{array}{l}\text { CFD HE } \\
\text { 20 tubes }\end{array}$ & $\begin{array}{l}\text { CFD HE } \\
\text { 24 baffles }\end{array}$ & $\begin{array}{l}\text { CFD HE } \\
26 \text { baffles }\end{array}$ \\
\hline$D_{\text {tube }}$ & $\mathrm{m}$ & 0.02 & 0.02 & 0.02 & 0.02 & 0.02 & 0.02 & 0.02 \\
\hline$D_{\text {shell }}$ & $\mathrm{m}$ & 0.18 & 0.18 & 0.18 & 0.18 & 0.18 & 0.18 & 0.18 \\
\hline$D_{\text {inlet } \text {, } h \text { ell }}$ & $\mathrm{m}$ & 0.0508 & 0.0508 & 0.0508 & 0.0508 & 0.0508 & 0.0508 & 0.0508 \\
\hline$S_{L}$ & $\mathrm{~m}$ & 0.03 & 0.03 & 0.03 & 0.03 & 0.03 & 0.03 & 0.03 \\
\hline$S_{T}$ & $\mathrm{~m}$ & 0.03 & 0.03 & 0.03 & 0.03 & 0.03 & 0.03 & 0.03 \\
\hline$S_{D}$ & $\mathrm{~m}$ & 0.03354 & 0.03354 & 0.03354 & 0.03354 & 0.03354 & 0.03354 & 0.03354 \\
\hline$B F$ & $\mathrm{~m}$ & 0.12 & 0.12 & 0.12 & 0.12 & 0.12 & 0.1223 & 0.113 \\
\hline$A_{\text {flow }}$ & $\mathrm{m}^{2}$ & 0.0216 & 0.0216 & 0.0216 & 0.0216 & 0.0216 & 0.022 & 0.0201 \\
\hline$D_{H-T}$ & $\mathrm{~m}$ & 0.02 & 0.02 & 0.02 & 0.02 & 0.02 & 0.02 & 0.02 \\
\hline$D_{H-S}$ & $\mathrm{~m}$ & 0.0296 & 0.0296 & 0.0296 & 0.0296 & 0.0296 & 0.0296 & 0.0296 \\
\hline$N$ & - & 16 & 16 & 16 & 12 & 20 & 16 & 16 \\
\hline$n$ & - & 25 & 25 & 25 & 25 & 25 & 24 & 26 \\
\hline$L$ & $\mathrm{~m}$ & 3.12 & 3.12 & 3.12 & 3.12 & 3.12 & 3.12 & 3.12 \\
\hline$C_{\text {tube }}$ & $\mathrm{m}$ & 0.01 & 0.01 & 0.01 & 0.01 & 0.01 & 0.01 & 0.01 \\
\hline
\end{tabular}

Table 3: Thermodynamic and fluid flow specifications of theoretical design and each CFD model

\begin{tabular}{|l:l|l|l|l|l|l|l|l|}
\hline Parameter & Unit & $\begin{array}{c}\text { Theoretical } \\
\text { values }\end{array}$ & $\begin{array}{c}\text { CFD HE } \\
20\end{array}$ & $\begin{array}{c}\text { CFD } \\
\text { HE 30 }\end{array}$ & $\begin{array}{c}\text { CFD } \\
\text { HE 12 } \\
\text { tubes }\end{array}$ & $\begin{array}{c}\text { CFD HE } \\
\text { 20 tubes }\end{array}$ & $\begin{array}{c}\text { CFD HE } \\
\text { 24 baffles }\end{array}$ & $\begin{array}{c}\text { CFD HE } \\
\text { 26 baffles }\end{array}$ \\
\hline$\rho_{h}$ & $\mathrm{~kg} / \mathrm{m}^{3}$ & 971.8 & 971.8 & 971.8 & 971.8 & 971.8 & 971.8 & 971.8 \\
\hline$\rho_{c}$ & $\mathrm{~kg} / \mathrm{m}^{3}$ & 995.7 & 995.7 & 995.7 & 995.7 & 995.7 & 995.7 & 995.7 \\
\hline$v_{\text {inlet, shell }}$ & $\mathrm{m} / \mathrm{s}$ & 1.25812 & 1.25812 & 1.25812 & 1.25812 & 1.25812 & 1.25812 & 1.25812 \\
\hline$v_{\text {tube }}$ & $\mathrm{m} / \mathrm{s}$ & 0.25 & 0.25 & 0.25 & 0.333 & 0.2 & 0.25 & 0.25 \\
\hline$\dot{m}_{h}$ & $\mathrm{~kg} / \mathrm{s}$ & 1.22 & 1.219 & 1.219 & 1.217 & 1.216 & 1.219 & 1.218 \\
\hline$\dot{m}_{c}$ & $\mathrm{~kg} / \mathrm{s}$ & 2.539 & 2.465 & 2.465 & 2.464 & 2.463 & 2.467 & 2.467 \\
\hline$q$ & $\mathrm{~W}$ & 204814 & - & - & - & - & - & - \\
\hline$\Delta T_{l m}$ & ${ }^{\circ} \mathrm{C}$ & 49.59 & - & - & - & - & - & - \\
\hline$T_{c, o}$ & ${ }^{\circ} \mathrm{C}$ & 39.3 & 42.43 & 39.85 & 35.54 & 40.78 & 40.49 & 39.34 \\
\hline$T_{h, o}$ & ${ }^{\circ} \mathrm{C}$ & 60 & 54.09 & 59.27 & 67.77 & 57.67 & 58.24 & 58.3 \\
\hline$R e_{s}$ & - & 13296 & - & - & - & - & - & - \\
\hline$R e_{t}$ & - & 13680.81 & - & - & - & - & - & - \\
\hline$\overline{N u}_{s}$ & - & 212.26 & - & - & - & - & - & - \\
\hline$\overline{N u}_{t}$ & - & 59.5 & - & - & - & - & - & - \\
\hline$h_{\text {shell }}$ & $\mathrm{W} / \mathrm{m}^{2} \mathrm{~K}$ & 4410.13 & - & - & - & - & - & - \\
\hline$h_{\text {tube }}$ & $\mathrm{W} / \mathrm{m}^{2} \mathrm{~K}$ & 1993.28 & - & - & - & - & - & - \\
\hline$U$ & $\mathrm{~W} / \mathrm{m}^{2} \mathrm{~K}$ & 1372.80 & - & - & - & - & - & - \\
\hline$\Delta P_{\text {shell }}$ & $\mathrm{Pa}$ & 10161.14 & 21650.94 & 9977.85 & 8593.63 & 11300.09 & 10059.58 & 10894.59 \\
\hline$\Delta P_{\text {tube }}$ & $\mathrm{Pa}$ & 136.82 & 174.20 & 148.26 & 234.46 & 115.34 & 225.45 & 174.77 \\
\hline$W_{\text {pump }}$ & $\mathrm{W}$ & 37.26 & 76.88 & 35.55 & 30.81 & 40.13 & 36.01 & 38.88 \\
\hline & & & & & & & & \\
\hline
\end{tabular}

In mesh creation, tetrahedrons elements were applied and also the important parameters such as the aspect ratio, skewness and number of elements were set carefully to create an accurate mesh and some of these details relating to the six models are given in Table 4. Also, a mesh convergence study was performed to ensure the accuracy.

Table 4: Specifications of the six CFD models

\begin{tabular}{|c|c|c|c|c|c|c|}
\hline Parameter & CFD HE 20 & $\begin{array}{c}\text { CFD HE } \\
30\end{array}$ & $\begin{array}{c}\text { CFD HE } \\
12 \text { tubes }\end{array}$ & $\begin{array}{c}\text { CFD HE } \\
20 \text { tubes }\end{array}$ & $\begin{array}{c}\text { CFD HE } \\
24 \text { baffles }\end{array}$ & $\begin{array}{c}\text { CFD HE } \\
26 \text { baffles }\end{array}$ \\
\hline $\begin{array}{c}\text { Number of } \\
\text { elements }\end{array}$ & 10407357 & 10455450 & 8594624 & 13671923 & 11265712 & 9946527 \\
\hline $\begin{array}{c}\text { Aspect } \\
\text { ratio } \\
\text { (maximum) }\end{array}$ & 26.95 & 20.91 & 24.86 & 20.91 & 19.42 & 22.24 \\
\hline $\begin{array}{c}\text { Skewness } \\
\text { (Average) }\end{array}$ & 0.2062376 & 0.2087387 & 0.2329403 & 0.2259929 & 0.2257553 & 0.2293346 \\
\hline
\end{tabular}

Four test trials were performed with different types of setup models in ANSYS FLUENT to find out the best settings for the heat exchanger modelling. Then, the settings were chosen with the energy equation on, the $K-\varepsilon$ model because of the turbulent flows in the shell as well as in the tubes, and also with the gravity on. Also, the nondimensional $\mathrm{y}+$ value was maintained within the acceptable range for a $K-\varepsilon$ model to achieve accurate results. A schematic of the CFD HE 30 model (with 16 staggered tubes) with its mesh arrangement is shown in Fig. 8.

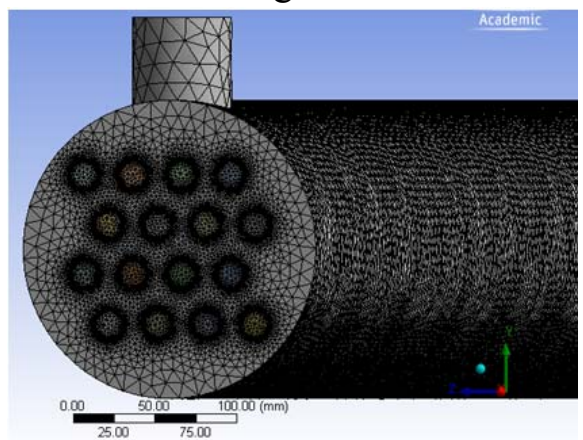

Fig. 8: CFD HE 30 design (with 16 tubes) with the generated mesh 


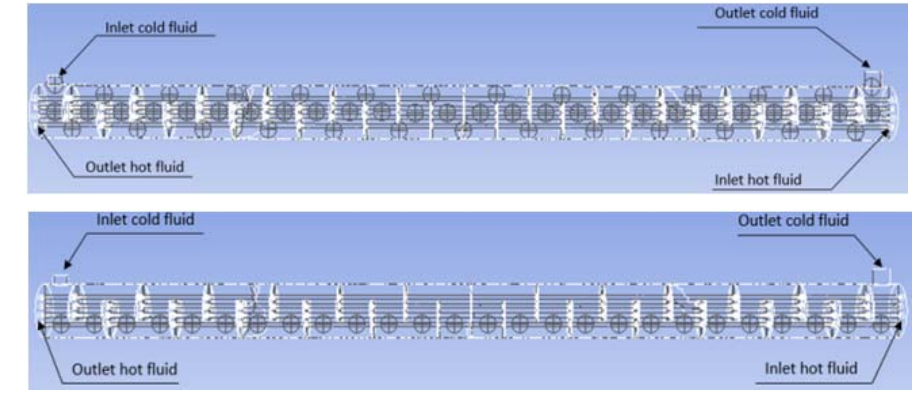

Fig. 9: Interested locations for parameter measurements for HE 30- tube side fluid (top), shell side fluid (bottom)

In each CFD model, 53 and 26 locations were marked to measure the interested parameters in shell and tube side flows, respectively, and these points related to CFD HE 30 model are shown in Fig. 9. The $1^{\text {st }}$ and $2^{\text {nd }}$ models (CFD HE 20 and CFD HE 30) were used mainly to investigate the effects of different baffle cut ratios. The other four models were implemented with the same baffle cut ratio $(30 \%)$ but with varying the number of tubes and baffles inside the shell by maintaining a constant mass flow rate, to analyse the changes in the parameters such as pressure drops, fluid outlet temperatures, and velocity distributions. Eventually, the most suitable shell-and-tube heat exchanger design will be selected with respect to the required outlet temperature of the hot fluid and the axial pressure drop of the heat exchanger.

\section{RESULTS AND DISCUSSION}

For all six CFD models, the axial temperature profiles showed a quite linear increase for the shell side fluid flow (cold fluid) and a decrease for the tube side flow (hot fluid) as was expected. However, the nature of the flow vortices were dependent upon the factors such as the flow velocity, baffle cut ratio, number of baffles and tubes, etc. The nature of the flow vortices for the CFD models, CFD HE 20 and CFD HE 30 are shown in Fig.10.

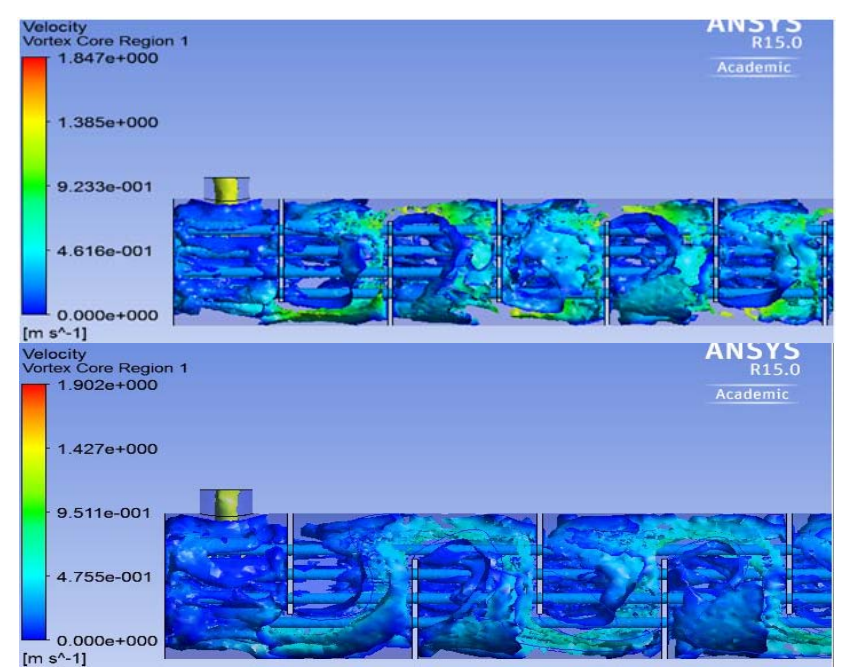

Fig. 10: Fluid flow behavior inside the shell of the heat exchanger: HE 20 (top) and HE 30 (bottom)

As it is evident, the fluid flow velocity increases as passes the baffles. Vortices are noticeable to the left side of each baffle. This type of a turbulent/mixing flow is promising for heat transfer enhancement but detrimental in terms of the pressure drop and hence with the pumping power demand as well. By comparing both HE 20 and HE 30 models (the only difference between these two models is the baffle cut ratio), the shell side fluid velocity and pressure drop increase with the increase of baffle cut ratio from $30 \%$ to $20 \%$. Owing to the increased vortex regions, HE 20 model shows better heat transfer performance (see Fig. 11) but with a higher pressure drop (see Fig. 12) and hence it shows an increase in pumping power as well (see $W_{\text {Pump }}$ in Table 3). Hence, this fact agrees with the claim made by Mukherjee [41], that finding of the right balance between the baffle cut ratio and baffle spacing is a key aspect of a well-optimized heat exchanger 
design in terms of thermal, constructional and energy aspects.

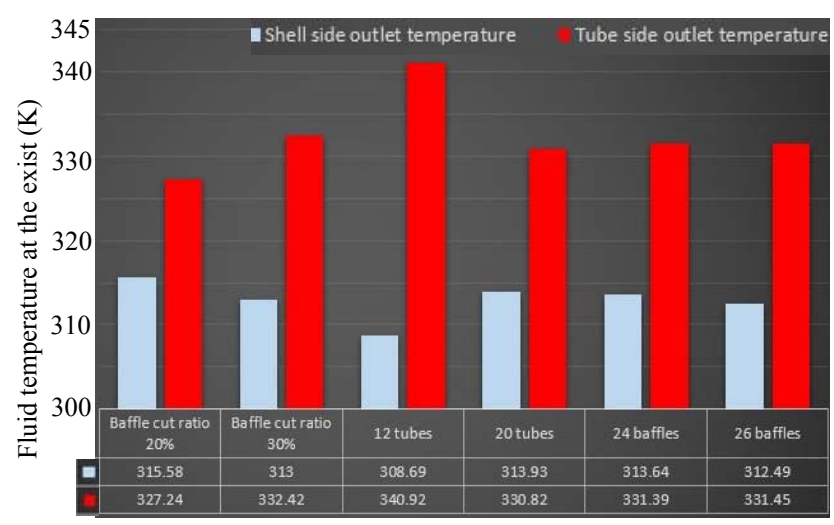

Fig. 11: Fluid flow outlet temperatures in shell and tube sides for 6 CFD models tested

The main purpose of the case study considered in this work is to cool down the hot fluid to $60{ }^{\circ} \mathrm{C}(333$ $\mathrm{K})$ at the heat exchanger outlet. Here, all six CFD models considered a heat exchanger with the same length and four of them are quite ok in achieving this expected output temperature where CFD HE 30 is the best, as shown in Fig. 11. Hence, it can be assumed that the chosen baffle spacing as well as the number of tubes in CFD HE 30 model provides the best combination to achieve the desired outcomes from the heat exchanger. Furthermore, this also proves the accuracy of the theoretical calculations performed for the required outlet temperatures with the LMTD method. As the number of tubes decreased from 16 to 12 (CFD HE 30 model to CFD HE 12 tubes model), the outlet temperature of the hot fluid is too high than the desired which might be due to the high flow velocity (hence less residence time for fluids exchanging heat) that should be required to maintain the desired mass flow rate with less number of tubes.
The shell and tube sides' axial pressure drops of all six CFD models were evaluated and details are illustrated in Fig. 12. The highest pressure drop $(21.65 \mathrm{kPa})$ occurs in the heat exchanger with a baffle cut ratio of $20 \%$ (CFD HE 20) where its pressure drop is almost the double compared to other five models. All the other five models are with a baffle cut ratio of $30 \%$ and among them the one with 20 tubes (CFD HE 20 tubes) marked the highest pressure drop (11.3 $\mathrm{kPa})$ which can be expected due to the lesser space for the shell side fluid with higher number of tubes. Obviously, the shell side pressure drop is always higher than the tube side mostly due to the complicated baffle placements and tubes.

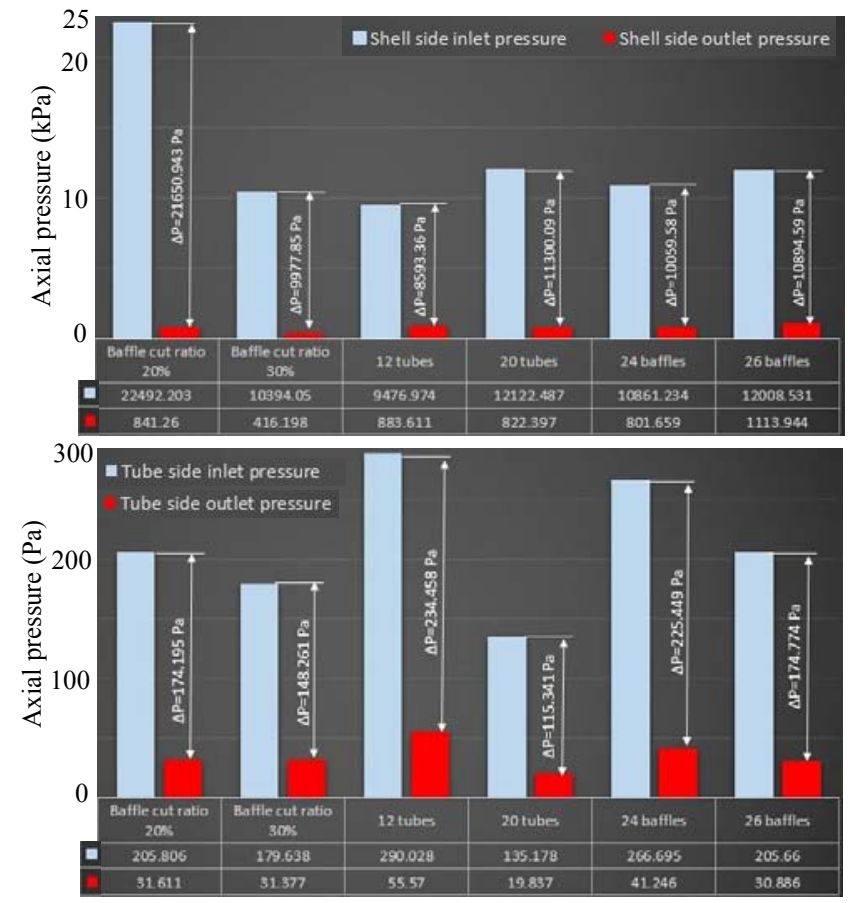

Fig. 12: Axial pressure drops of 6 CFD models: shell (top), tubes (bottom)

As it is clear from Fig. 12, the heat exchanger design with 12 tubes (the lowest tube number of all designs) shows the lowest pressure drop inside the shell (also demanded the highest inlet velocity) 
which can be appreciated. Furthermore, increase of the number of baffles has also caused to increase the pressure drop and this is in agreement with many of the previous works $[41,48]$. The highest tube side pressure drop occurs in the HE model with 12 tubes and this is due to the demand of high inlet velocity to maintain the mass flow rate. The heat exchanger with 20 tubes demands the lowest fluid flow velocity and hence the smallest tube side pressure drop. A comparison of the shell side fluid velocities for the six models (listed in Tables 2 and 3) are shown in Fig. 13 and all sub figures are in the same scale for the ease of comparison. Here, CFD HE 20 model marked the highest shell side velocity among the six models and this is not surprising as its baffle cut ratio is $20 \%$ while others are with $30 \%$.

Overall, of the six designs, CFD HE 30 shows the most favourable results in terms of the expected outcomes and the pumping power demand. In addition to the six models discussed in this paper, there are some other possible ways to alter the thermodynamic parameters of the heat exchanger, such as use of different flow or tube-banks arrangements. Use of an aligned tube-bank instead a staggered tube-bank would cause to decrease the Nusselt number of the shell side fluid given that the pitch ratio is the same. With this effect, the heat transfer coefficient for the shell side fluid would be reduced to 3895 from $4410 \mathrm{~W} \cdot \mathrm{m}^{-2} \cdot \mathrm{K}^{-1}$. If a parallel flow was used instead of a counter flow, the logarithmic mean temperature difference would decrease to $43.86{ }^{\circ} \mathrm{C}$ from $46.59{ }^{\circ} \mathrm{C}$ and then total length of the heat exchanger would increase to 3.55 $\mathrm{m}$ from $3.12 \mathrm{~m}$ (see Table 3 ). These imply the possible complexity and considerations of heat exchanger design and hence design optimization is necessary to have compact heat exchangers.

The impact of changing vital design parameters is obvious from the results of the six CFD models tested. Obviously, the correct combination of baffle spacing and baffle cut ratio is a key to the performance of a heat exchanger. As was realized from the CFD models, decreasing the baffle cut ratio below $30 \%$ will greatly influence the pressure drop and the required outlet temperature and this is in agreement with the findings/claims made previously [21-39]. Based on both CFD modelling and theoretical calculations, it showed that $30 \%$ baffle cut ratio is the most efficient for the given design and hence five CFD models were implemented with $30 \%$ baffle cut ratio and then they were used to analyse the effect of other parameters such as the number of tubes and baffles. Theoretically, the desired hot fluid exit temperature was $60{ }^{\circ} \mathrm{C}$ and this was achieved as $59.27{ }^{\circ} \mathrm{C}$ with CFD HE 30 model. The percentage mismatch of hot fluid's exit temperature (theoretical to CFD) is as small as $1.05 \%$. Moreover, as was mentioned, CFD HE 30 model was able to achieve a lower pressure drop compared to CFD HE 20 model. For the CFD HE 30 , the pressure drops in shell and tube sides were $9978 \mathrm{~Pa}$ and $148 \mathrm{~Pa}$, respectively. The corresponding theoretical values were $10162 \mathrm{~Pa}$ and $137 \mathrm{~Pa}$, respectively. Here, the percentage mismatches of pressure drops (theoretical to CFD) for shell and tube sides are $1.81 \%$ and $-8.03 \%$, respectively. These 

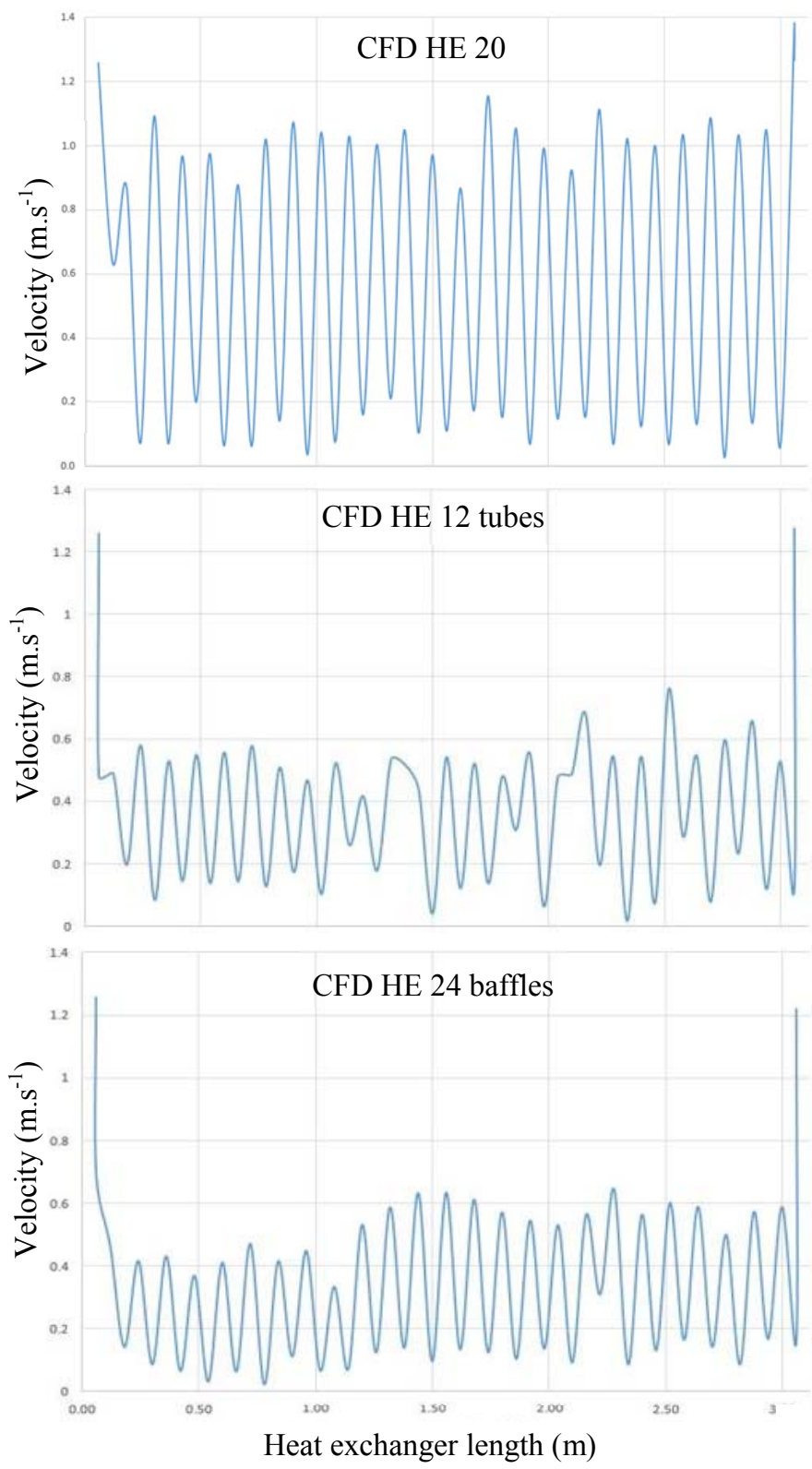

Fig. 13: Velocity profiles of the shell side flow for the six CFD models tested
CFD HE 30

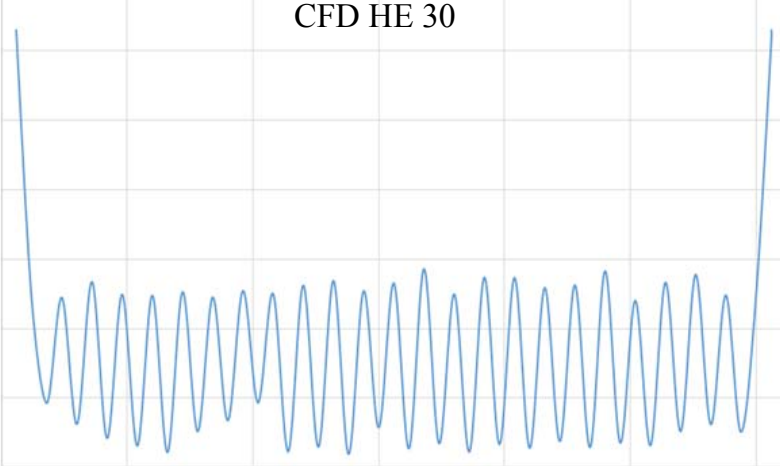

CFD HE 24 tubes

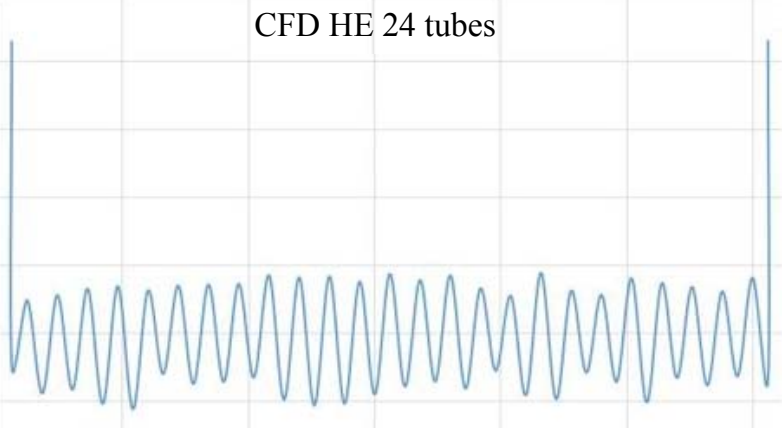

CFD HE 26 baffles

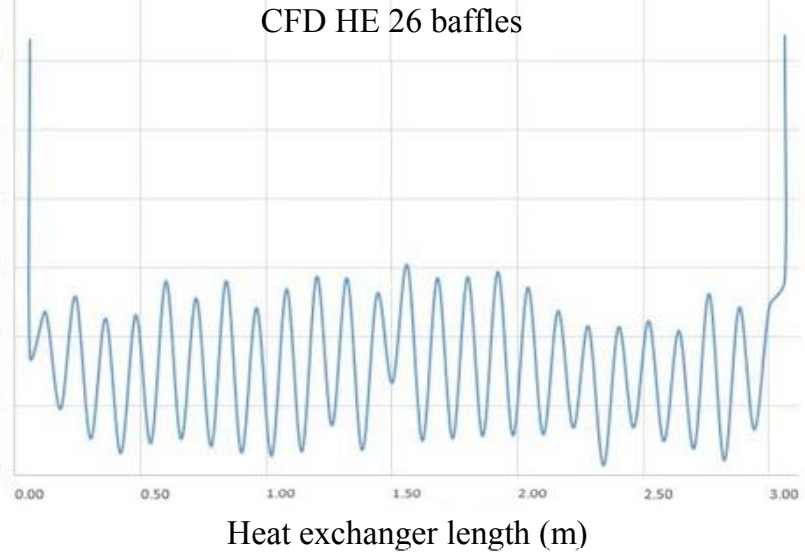

differences in theoretical and CFD results should mostly be due to the assumptions (mentioned in Section 3) attributed with the theoretical calculations. For example, in the theoretical calculations, it was assumed that there is no heat loss to the surroundings. But in the CFD simulation this assumption can be avoided as ANSYS can calculate the heat loss to the surroundings. Furthermore, the accuracy of the CFD results depends on the nature/quality of the mesh development as well. Hence, in this study, a detailed investigation was made on the effect of the size, type and the number of mesh elements on the accuracy of the results prior to implementing six CFD models. Generally, the result of this work confirms that the theoretical and CFD results are in good agreement. Moreover, the pressure drop studies of this work verify that the Kern method is a reliable way to calculate the 
pressure drop, although Ozden et al. [28] have reported issues of using this method (and recommend the Bell Delaware method). Indeed, the Bell-Delaware method seems to be more accurate as it accounts a number of correction factors. The total pumping power required for the heat exchanger was also calculated theoretically by following the method proposed by Liu et al [21] and gave a value of 37.26 $\mathrm{W}$, however this was not able to be determined with CFD. Hence, the pumping power required for each CFD model was calculated by hand with the mass flow rates and pressure drops of each model. The power demand of each model is in agreement with the trend of pressure drop and is acceptable; for example, the power demand of the CFD HE 30 model is $35.55 \mathrm{~W}$ and is quite close to the theoretical design (37.26 W). The CFD HE 20 demands the highest pumping power which has the highest pressure drop in shell side among the six models tested. Overall, the findings of this work show a good agreement between theoretical and CFD results and also it seems that CFD is a promising tool to design compact heat exchangers by optimizing the performance when used with a proper theoretical validation.

\section{CONCLUSIONS AND FUTURE WORK}

Obviously, a sound knowledge in thermodynamics, fluid dynamics and CFD is crucial for the design and optimization of a compact heat exchanger. In this work, six CFD models were developed and the accuracy of these was validated via a detailed theoretical calculation. Based on the
CFD results, it was recognized that a careful selection of parameters such as the baffle cut ratio, number of baffles and tubes, flow and tube arrangements are vital in optimizing the performance of a shell-and-tube heat exchanger for a given heat load. Of the six CFD models tested, CFD HE 30 model (with $30 \%$ baffle cut ratio, 16 tubes and 25 baffles) gave the best performance in accomplishing the desired task and this is well-aligned with the theoretical results as well. A decrease in baffle cut ratio increases the heat transfer coefficient in shell side but this also causes to increase the pressure drop. Obviously, the number of tubes used within a heat exchanger has an influence on tube flow velocity to maintain the required mass flow rate, where the lower the number of tubes the higher the pressure drop for a given task. More importantly, findings of this work are in agreement with the previously reported research and this proves the accuracy of the findings made. In terms of achieving the desired hot fluid exit temperature, theoretical and CFD results showed a mismatch of only around $1.05 \%$. For the pressure drops in shell and tube sides, these mismatches were $1.81 \%$ and $-8.03 \%$, respectively. Overall, the results of this work confirm that CFD modelling is promising for design and optimization of a heat exchanger. In future work, it is recommended to identify the effects of tube material (such as replacing steel with copper) and dimensions (diameter and thickness) on the optimization particularly to achieve a more compact design. Also, other practical issues such as fouling, corrosion, vibrations, thermal leakages and dead 
zones should be analysed for improved designs. Furthermore, the component failure modes should also be tested to optimize their dimensions and this should help to achieve the best possible compact heat exchanger design with an optimal thermal efficiency.

\section{NOMENCLATURE}

\section{Symbol-Description}

$A_{\text {flow }}-$ Cross flow area of the tube bank

$A_{\text {tube }}-$ Cross flow area of a tube

$A_{\mathrm{s}}$ - Flow area between two fluids

$B F$ - Baffle spacing

$c_{p}$ - Specific heat capacity at constant pressure

$C_{\text {tube }}-$ Clearance between tubes

$D_{\mathrm{H}-\mathrm{S}}, D_{\mathrm{H}-\mathrm{T}}-$ Hydraulic diameters of the shell and tube sides [m]

$D_{\text {inlet, shell }}$ - Inlet diameter to the shell

$D_{\text {shell }}$ - Diameter of the shell

$D_{\text {tube }}$ - Diameter of the tube

$F_{\text {shell }}, f_{\text {tube }}$ - friction factors of shell and tube flow s

$F$ - Correction factor

$G_{s}$ - Mass velocity of the shell side fluid

$h_{\text {shell }}, h_{\text {tube }}$ - heat transfer coefficient in shell and tube sides [W. $\mathrm{m}^{-2} . \mathrm{K}$ ]

$k$ - Thermal conductivity

$L$ - Length of the tubes

$n$-Number of baffles inside the shell

$\dot{m}_{h}, \dot{m}_{c}$ - mass flow rates of the hot and cold fluids

$N$ - Number of tubes inside the shell

$N_{L}$ - number of rows in the tube bank

$N_{R}$ - number of tubes in a row

$\overline{N u}_{s}, \overline{N u}_{t}$ - Nusselt number in shell and tube sides

$\mathrm{Pr}$ - Prandtl number

$q$ - heat load

$R e_{\mathrm{s}}, R e_{\mathrm{t}}-$ Reynols number in shell and tube sides

$S_{\mathrm{L}}$ - Longitudinal pitch

$S_{\mathrm{T}}-$ Transverse pitch

$S_{\mathrm{D}}$ - Diagonal pitch

$T_{\mathrm{h}, \mathrm{o}}, T_{\mathrm{c}, \mathrm{o}}-$ outlet temperature of hot and cold fluids

$U$ - Overall heat transfer coefficient

$v_{\text {inlet,shell }}-$ inlet velocity of shell side

$v_{\text {tube }}$ - velocity of fluid inside the tubes

$\Delta T_{\operatorname{lm}}$ - Log mean temperature difference

$\Delta P_{\text {shell }}, \Delta P_{\text {tube }}-$ Pressure drop in shell and tube sides

$W$ - Total power consumption

$\rho_{\mathrm{h}}, \rho_{\mathrm{c}}-$ density of hot and cold waters

$\mu$-Viscosity

$\varphi_{s}$ - the viscosity correction factor for the shell side fluid

$\eta_{\text {pump }}-$ Efficiency of the pump

$C_{1}, C_{2}, m$-Constants associated with Nusselt number

$P, R-$ Constants associated with correction factor cahrt

\section{Subscripts}

avg - average

$c$ - cold fluid $h$ - hot fluid

$i-$ inlet conditions

$o-$ outlet conditions

$s$ - shell side flow

$t$ - tube side flow

\section{ACKNOWLEDGEMENTS}

Assistance provided by D. Grundmeier in performing CFD modelling is greatly appreciated.

\section{REFERENCES}

[1] Y. Cengel, Introduction to Thermodynamics and Heat Transfer, McGraw-Hill Education; 2 Ed, 2010.

[2]N. V. Suryanarayana, Engineering Heat Transfer, West Publishing Company, USA, 1995.

[3]F. P. Incropera, D. P. DeWitt, T. L. Bergman, A. S Lavine, Fundamentals of Heat and Mass Transfer, Wiley, USA, 2006.

[4]F. M. White, Heat and Mass Transfer, AddisonWesley Publishing Company, USA, 1991.

[5] T. D Eastop and A. McConkey, Applied Thermodynamics for Engineering Applications, Longman Publishers, Singapore, 1993.

[6] A. Dewan, P. Mahanta, K. S. Raju and P. S. Kumar, Review of passive heat transfer augmentation techniques, Proc. of the Institutions of Mechanical Engineers -Part A: Journal Power and Energy, 218 (7), 509-527, 2004.

[7]A. Gupta and M. Uniyal, Review of heat transfer augmentation through different passive intensifier methods, IOSR Journal of Mechanical and Civil Engineering, 1 (4), 14-21, 2012.

[8] N. K. Nagayach, A. B. Agrawal, Review of heat transfer augmentation in circular and non-circular tube, International Journal of Engineering Research and Applications, 2 (5), 796-802, 2012.

[9] A. B. Ganorkar and V. M. Kriplani, Review of heat transfer enhancement in different types of extended surfaces, International Journal of Engineering Science and Technology, 3 (4), 3304-3313, 2011.

[10] K. Stone and S. P. Vanka, Review of Literature on Heat Transfer Enhancement in Compact Heat Exchangers, Available at: https://ideals.illinois.edu/bitstream/handle/2142/1154 0/TR105.pdf?sequence=2, A report prepared by Air 
Conditioning and Refrigeration Center, University of Illinois, August 1996.

[11] C. Abeykoon, Improving the Performance of Shelland-Tube Heat Exchangers by the Addition of Swirl, International Journal of Process Systems and Engineering, 2 (3), 221-245, 2014.

[12] S. Eiamsa-ard and P. Promvonge, Enhancement of heat transfer in a tube with regularly-spaced helical tape swirl generators, Solar energy, 78 (4), 483-484, 2005.

[13] R. M. Manglik and A. E. Bergles, Heat transfer and pressure drop correlations for twisted-tape inserts in isothermal tubes, Part I. Laminar flows, ASME Journal of Heat Transfer, 115 (4), 881-889, 1993.

[14] R. M. Manglik and A. E. Bergles, Heat transfer and pressure drop correlations for twisted-tape inserts in isothermal tubes: Part II-Transition and turbulent flows. ASME Journal of Heat Transfer, 115 (4), 890-896, 1993.

[15] S. W. Hong and A. E. Bergles, Augmentation of laminar flow heat transfer in tubes by means of twisted-tape inserts, ASME Journal of Heat Transfer, 98 (2), 251-256, 1976.

[16] S. Eiamsa-ard, C. Thianpong and P. Promvonge, Experimental investigations of heat transfer and pressure drop characteristics of flow through circular tube fitted with regularly-spaced twisted tape, The Joint International Confernce on Sustainable Energy and Environment, Hua Hin, Thailand, pp 18-22, 2004.

[17] F. Chang and V. K. Dhir, Mechanisms of heat transfer enhancement and slow decay of swirl in tubes using tangential injection, International Journal of Heat and Fluid Flow, 16 (2), 78-87, 1995.

[18] C. Yildiz, Y. Bicer and D. Pehlivan, Influence of fluid rotation on the heat transfer and pressure drop in double pipe heat exchangers. Applied Energy 54 (1), 49-56, 1996.

[19] M. Awais and A. A. Bhuiyan, Heat transfer enhancement using different types of vortex generators (VGs): a review on experimental and numerical activities. Thermal Science and Engineering Progress 5, 524-545, 2018.
[20] M. Awais, M. and A. A. Bhuiyan, Enhancement of thermal and hydraulic performance of compact finned-tube heat exchanger using vortex generators (VGs): A parametric study. International Journal of Thermal Sciences 140, 154-166, 2019.

[21] W. Liu, S. R. Oh, J. Yang, Optimization of shelland-tube heat exchangers using a general design approach motivated by constructal theory, International Journal of Heat and Mass Transfer 77(2014) 1144-1154, 2014.

[22] M. Amidpour, A.V. Azad, Economic optimization of shell and tube heat exchanger based on constructal theory, Energy 36 (2011) 1087-1096

[23] H. Hajabdollahi, S. Sanaye, Multi-objective optimization of shell and tube heat exchangers, Applied Thermal Engineering 30 (2010) 1937-1945

[24] V. K. Patel, R.V. Rao, (2010), Design optimization of shell-and-tube heat exchanger using particle swarm optimization technique, Applied thermal engineering 30 (2010) 1417-1425

[25] D. Di Benetto, S. Montelpare, R. Ricci, R. Romagnoli, Convective heat transfer increase in internal laminar flow using a vibrating surface, International Journal of Thermal Sciences 84 (2014) 358-368

[26] J. Fukai, H. Mitani, K. Nakaso, (2014), Convection heat transfer in a shell and tube heat exchanger using sheet fins for effective utilization of enregy, International Journal of Heat and Mass Transfer 82 (2015) 581-587

[27] A. S. Wilson, M.K. Bassiouny, Modelling of heat transfer for flow across tube banks, Chemical Engineering and Processing: Process Intensification 39 (2000) 1-14

[28] E. Ozden, I. Tari, Shell side CFD analysis of a small shell-and-tube heat exchanger, Energy Conversion and Management, 51 (2010) 1004-1014

[29] J. Bock, A. M. Jacobi, W. Liu, L. Ma, J. Yang, A comparison of four numerical modelling approaches for enhanced shell-and-tube heat exchangers with experimental validation, Applied Thermal Engineering, 65 (2014) 369-383

[30] J. Liu, W. Liu, L. Ma, J. Yang, Thermal-hydraulic performance of a novel shell-and-tube oil cooler with multi-fields synergy analysis, International Journal of Heat and Mass Transfer, 77 (2014) 928-939 
[31] M. Picon-Nunez, G. T. Polley, G. MartinezRodriguez, Graphical tool for the preliminary design of compact heat exchangers, Applied Thermal Engineering 61 (2013) 36-43

[32] B. V. Babu, S. A. Munawar, Differential evolution strategies for optimal design of shell-and-tube heat exchangers, Chemical Engineering Science 62 (2007) 3720-3739

[33] M. Fesanghary, E. Damangir, I. Soleimani, Design optimization of shell and tube heat exchangers using global sensitivity analysis and harmony search algorithm, Applied Thermal Engineering 29 (2009) 1026-1031

[34] J. M. Ponce- Ortega, M. Serna-Gonzalez, A. Jimenez-Gutierrez, Use of genetic algorithms for the optimal design of shell-and-tube heat exchangers, Applied Thermal Engineering 29 (2009) 203-209

[35] A.C. Caputo, P.M. Pelagagge, P. Salini, Heat exchanger design based on economic optimization, Applied Thermal Engineering 28 (2008) 1151-1159

[36] A. Hadidi, A. Nazari, Design and economic optimization of shell-and-tube heat exchangers using biogeography-based (BBO) algorithm, Applied Thermal Engineering 51 (2013) 1263-1272

[37] J. Yang, A.W. Fan, W. Liu, A.M Jacobi, Optimization of shell and tube heat exchangers conforming to TEMA standards with designs motivated by constructal theory, Energy Conversion and Management 78 (2014) 468-476

[38] Y. Özcelik, Exergetic optimization of shell and tube heat exchangers using a genetic based algorithm, Applied Thermal Engineering 27 (2007) 1849-1856

[39] J. F. Guo, L. Cheng, M. T. Xu, Optimization design of shell and tube heat exchanger by entropy generation minimization and genetic algorithm, Applied Thermal Engineering 29 (2009) 2954-2960.

[40] S. Wang, J. Wen and Y. Li, An experimental investigation of heat transfer enhancement for a shell-and-tube heat exchanger, Applied thermal engineering, 29 (11-12), 2433-2438, 2009.

[41] R. Mukherjee, Effectively design of shell-and-tube heat exchangers, Chemical Engineering Progress 94 (1998) 21-37

[42] TEMA (2007) Standards of The Tubular Exchanger Manufacturers Association, ninth ed. Tubular Exchanger Manufacturers Association, New York.
[43] R. K. Shah, D.P. Sekulic, (2003), Fundamentals of heat exchanger design, New Jersey, Wiley, USA.

[44] A. Bejan, Shape and structure, from engineering to nature, Cambridge, UK, Cambridge University Press, 2000.

[45] S. Fettaka, J. Thibault and Y. Gupta, Design of shelland-tube heat exchangers using multi-objective optimization, International Journal of Heat and Mass Transfer 60, 343-354, 2013.

[46] K. N. Ahmad, M. H. Bashir, M.M.A. Bhutta, N. Hayat, A.R. Khan, S. Khan, CFD applications in various heat exchangers design: A review, Applied Thermal Engineering, 32 (2012) 1-12.

[47] E. Pal, I. Kumar, J. B. Joshi and N.K.Maheshwari, CFD simulations of shell-side flow in a shell-andtube type heat exchanger with and without baffles, Chemical EngineeringScience143, 314-340, 2016.

[48] P. Bichkar, O. Dandgaval, P. Dalvi, R.Godase and T. Dey, Study of Shell and Tube Heat Exchanger with the Effect of Types of Baffles, Procedia Manufacturing 20, 195-200, 2018.

[49] N. H. S. Tay, F. Bruno and M. Belusko, Experimental validation of a CFD and an $\varepsilon$-NTU model for a large tube-in-tank PCM system, International Journal of Heat and Mass Transfer 55, 5931-5940, 2012.

[50] S. M. Shahril, G. A. Quadir, N. A. M. Amin, and I. A. Badruddin, Thermo hydraulic performance analysis of a shell-and-double concentric tube heat exchanger using CFD, International Journal of Heat and Mass Transfer,105,781-798, 2017.

[51] A. Jimenez, M. Serna, A compact formulation of the Bell-Delaware method for heat exchanger design and optimization, Chemical Engineering Research and Design 83 (2005) 539-550.

[52] J. Yang, M. Zeng and Q. Wang, Numerical investigation on combined single shell-pass shelland-tube heat exchanger with two-layer continuous helical baffles, International Journal of Heat and Mass Transfer 84, 103-113, 2015.

[53] Y. Wang, X. Gu, Z. Jin, K. Wang, Characteristics of heat transfer for tube banks in crossflow and its relation with that in shell-and-tube heat exchangers, 
International Journal of Heat and Mass Transfer 93, 584-594, 2016.

[54] M. Awais and A. A. Bhuiyan, Heat and mass transfer for compact heat exchanger (CHXs) design: A stateof-the-art review, International Journal of Heat and Mass Transfer 127, 359-380, 2018.

[55] M. M. A. Bhutta, N. Hayat, M. H. Bashir, A. R. Khan, K. N. Ahmad, and S. Khan, CFD applications in various heat exchangers design: A review, Applied Thermal Engineering, 32, 1-12, 2012.

[56] A. A.Al-abid, S. B. Mat, K. Sopian, M. Y. Sulaiman, A. Th. Mohammed, CFD applications for latent heat thermal energy storage: a review, Renewable and Sustainable Energy Reviews, 20, 353-363, 2013.

[57] D. Southall, R. Le Pierres, and S. J. Dewson, Design Considerations for Compact Heat Exchangers, Paper 8009, Proceedings of ICAPP '08 Anaheim, CA USA, June 8-12, 2008.

[58] D. Southall and S. J. Dewson, Innovative Compact Heat Exchangers, Paper 10300, Proceedings of ICAPP '10 San Diego, CA, USA, June 13-17, 2010.

[59] D.Q. Kern, (1950), Process Heat Transfer, McGraw-Hill, USA.

[60] N. Haribabu, C.J. Rao, G.V. Srinivasa Rao, Heat Transfer Analysis on Shell and Tube Heat Exchangers, International Journal of Research in Aeronautical and Mechanical Engineering 2 (2014) 11-26. 